\title{
МЕТОД ГІЛОК І МЕЖ У КАЛЕНДАРНОМУ ПЛАНУВАННІ ВАНТАЖНО- ВИВАНТАЖУВАЛЬНИХ РОБІТ
}

\author{
Канд. техн. наук В.С. Меркулов, старш. викл. І.Г. Бізюк
МЕТОД ВЕТВЕЙ И ГРАНИЦ В КАЛЕНДАРНОМ ПЛАНИРОВАНИИ ПОГРУЗОЧНО- ВЫГРУЗОЧНЫХ РАБОТ

\author{
Канд. техн. наук В.С. Меркулов, старш. преп. И.Г. Бизюк
}

\section{BRANCH AND BOUND METHOD IN SCHEDULING OF LOADING-UNLOADING OPERATION}

\author{
Cand. of techn. sciences V. Merkulov, I. Biziuk
}

Стаття присвячена питанням, пов'язаним з перевезеннями вантажів. Розглянуто застосування методу гілок $i$ меж у якості математичного апарату алгоритму планування вантажно-вивантажувальних робіт.

Необхідно розв'язати зміману задачу лінійного програмування: мінімізувати цілльову функцію, що залежить від директивних і планових показників, частина з яких приймає ијілі значення а решта рачіональні.

Запропонована модель адекватно описує предметну область, що дозволило на ї̈ базі розробити і впровадити на Південній залізниці ефективну програмну систему.

Ключові слова: оперативне планування, вантаження-вивантаження, автоматизація, регулювальне завдання, норми вантажної роботи, цілочисельне лінійне програмування, показники, метод гілок і меж, галуження, иільова функиія.

Статья посвящена вопросам, связанным с грузоперевозками. Рассмотрено применение метода ветвей и грании в качестве математического аппарата алгоритма планирования погрузочновыгрузочных работ.

Необходимо решить смешанную задачу линейного программирования: минимизировать целевую функцию, которая зависит от директивных и плановых показателей, часть которых принимает целье значения, а остальные - рачиональнье.

Предложенная модель адекватно описывает предметную область, что позволило на ее базе разработать и внедрить на Южной дороге эффективную программную систему.

Ключевые слова:, оперативное планирование, погрузка-выгрузка, автоматизация, регулировочное задание, нормы грузовой работы, челочисленное линейное программирование, показатели, метод ветвей и грании, ветвление, целевая функиия.

The article considers the problems connected with cargo transporting. The appliance of the branch and bound method as a mathematical machinery of algoritm of the scheduling of loading-uploading operation is considered.

It is necessary to solve a mixed problem of linea programming $(L P)$, specifically to minimize the target function, which depends on directive and planned indicators, which part takes up the whole integral values while the rest are rational.

The suggested model sufficiently describes the object region which base allows it to develop and involve an effective program system on the Southern Railway.

$L P-2$ and LP-3.If optimal solutions of the problems LP-2 and LP-3 consist of non-integral values, then we enter new limits at the next expansion.

The process of branching and the task solution of LP continues until the obtaining of integer-valued optimal solution of one of the subtasks of LP.

In the use of the branch and bound method the choice of the top of the further branching is performed until there is at least one nonintegral variable. 
The sufficiency of the method significantly depends on the speed of serial sounding tops.

Keywords: operative planning, loading-unloading, automation, regulating task, rates of cargo operations, linear integer programming, figures, the branch and bound method, branching,objective function.

Вступ. Постановка проблеми. Автоматизації процесу оперативного планування вантаження-вивантаження передбачає розроблення відповідного математичного апарату, який можна покласти в основу опису предметності області та побудови алгоритму отримання породового регулювального завдання і норм вантажної роботи $[1$, с. $8 ; 2$, c. $7 ; 3$, c. 21$]$.

Основний матеріал. Маємо змішану задачу лінійного програмування (ЛП): мінімізувати цільову функцію

$$
F=F\left(X_{t}\right)=F\left(\sum_{j=1}^{J} \bar{x}_{t}^{j}\right) \approx \sum_{j=1}^{J} \sum_{k=1}^{K} x_{t}{ }^{j k},
$$

де директивні показники: $X_{t}$ - регулювальне завдання по регіону в цілому;

$\bar{x}_{t}^{j}$ - регулювальне завдання по кожній $j$-й станції на $t$-й інтервал планового періоду;

показники, щуо плануються: $x_{t}^{j k}-$ норми вантажної роботи по $k$-му роду вантажних вагонів $j$-ї станції на $t$-й інтервал планового періоду;

$$
\begin{aligned}
& j=1,2, \ldots, J-\text { порядковий номер станції; } \\
& k=1,2, \ldots, K-\text { порядковий номер роду }
\end{aligned}
$$
вантажних вагонів при обмеженнях

$$
\left|\sum_{j=1}^{J} \sum_{k=1}^{K} x_{t}^{j k}\right|=b,
$$

де $b \approx\left|\tilde{X}_{t}\right| ; \tilde{X}_{t}$ - директивне регулювальне завдання по регіону в цілому.

Частина змінних приймає цілі значення $x{ }_{t}^{j k} \in Z$, а частина - раціональні $x_{t}^{j k} \in Q$, де $Z$ - множина цілих чисел; $Q$ - множина раціональних чисел $[4$, с. $161 ; 5$, с. 8$]$.

Задача календарного планування на першому кроці може бути сформульована як задача ЛП. При цьому припускаємо, що всі змінні - величини безперервні. Отриману задачу позначимо як ЛП-1; оптимальне значення ії цільової функції дорівнює $F_{1}$. В оптимальному розв'язку задачі ЛП-1 деякі цілочисельні змінні можуть мати нецілі значення. Тоді оптимальний розв'язок вихідної задачі не збігається з оптимальним розв'язком ЛП-1.

Для визначення змінної, по якій робимо галуження, застосуємо довільні правила вибору. Наприклад, можна обрати змінну 3 найменшим номером.

Нехай галуження відбувається по цілочисловій змінній $x_{t}^{j_{1} k_{1}}$, неціле значення якої в оптимальному розв'язку ЛП-1 дорівнює $x_{t}^{j_{1} k_{1}^{*}}$. Далі розглянемо дві нові підзадачі вихідної задачі, які позначимо як ЛП-2 і ЛП-3. Вони виникають внаслідок введення обмежень відповідно $\left.x_{t}^{j_{1} k_{1}} \leq\right] x_{t}^{j_{1} k_{1}{ }^{*}}\left[\right.$ та $\left.x_{t}^{j_{1} k_{1}} \geq\right] x_{t}^{j_{1} k_{1}{ }^{*}}[$, де $] x[$ - ціла частина $x$.

Таким чином, вихідну задачу ЛП можна записати як сукупність двох підзадач ЛП-2 і ЛП-3 у такий спосіб: мінімізувати $F\left(X_{t}\right)$ при обмеженнях

ЛП-2:

$$
\begin{aligned}
& \left.\left|\sum_{j=1}^{J} \sum_{k=1}^{K} x_{t}^{j k}\right|=b ; x_{t}^{j_{1} k_{1}} \leq\right] x_{t}^{j_{1} k_{1} *}\left[; \quad x_{t}^{j k} \geq 0 ;\right. \\
& \left.\left|\sum_{j=1}^{J} \sum_{k=1}^{K} x_{t}^{j k}\right|=b ; \quad x_{t}^{j_{1} k_{1}} \geq\right] x_{t}^{j_{1} k_{1}{ }^{*}}\left[; \quad x_{t}^{j k} \geq 0 .\right.
\end{aligned}
$$

Якщо оптимальні розв'язки задач ЛП-2 i ЛП-3 також містять нецілі значення, то на черговому кроці вводимо нові обмеження, керуючись таким правилом: для здійснення подальшого галуження обираємо ту вершину, що відповідає оптимальному значенню цільової функції. Після визначення вершини галуження обираємо цілочисельну змінну, яка має в оптимальному розв'язку відповідної задачі ЛП неціле значення, і здійснюємо галуження по цій змінній. Процес галуження та розв'язування 
задачі ЛП продовжується до одержання цілочисельного оптимального розв'язку однієї 3 підзадач ЛП. Значення $F$ в отриманій точці являє собою верхню межу оптимального значення цільової функції вихідної задачі иілочисельного лінійного програмування (ЦЛП). На цьому етапі відкидаються задачі ЛП, для яких оптимальне значення $F$ не менше отриманої верхньої межі. При використанні методу гілок $i$ меж вибір вершин для подальшого галуження робимо доти, поки залишається хоча б одна неціла змінна (3 обмеженням цілочисельності).

Ефективність методу залежить значною мірою від швидкості послідовного зондування вершин. При цьому повинна виконуватися хоча б одна $з$ таких умов:

а) оптимальний розв'язок, що відповідає даній вершині, цілочисельний, тобто $x_{t}^{j k^{*}} \in Z$; б) оптимальне значення $F$ відповідної задачі ЛП не менше від поточної нижньої межі;

в) задача ЛП, що відповідає розглянутій вершині, не має припустимих значень.

Висновки. Для перевірки виконання умов а) і б) потрібний значний час, а умову в) не можна використовувати для визначення нижньої межі для задачі ЦЛП, тобто для одержання початкового плану (регулювального завдання). Але оскільки наявність перед застосуванням методу гілок і меж припустимого цілочисельного розв'язку досить бажана, пропонується за нульове наближення значень вектора $\bar{x}_{t}^{j^{*}}$ прийняти значення, розраховані на ЕОМ за алгоритмом існуючої «ручної» технології.

\section{Список використаних джерел}

1. Самсонкін, В.М. Ситуаційно-евристичний підхід до календарного планування вантажнорозвантажувальних робіт в регіоні залізниці [Текст] / В.М. Самсонкін, В.С. Меркулов // Залізничний транспорт України. - 2007. - № 4. - С. 8-10.

2. Самсонкин, В.Н. Концепция построения автоматизированной системы оперативного планирования погрузочно-выгрузочных работ и ведения штатного расписания в регионе дороги [Текст] / В.Н. Самсонкин, В.С. Меркулов // Залізничний транспорт України. - 2008. - № 3. - С. 6-10.

3. Меркулов, В.С. Удосконалення технології календарного планування вантаження та розвантаження. [Текст] / В.С. Меркулов // Інформаційно-керуючі системи на залізничному транспорті. - 2010. - № 4. - С. 21-22.

4. Самсонкин, В.Н. Моделирование организационного механизма распределения ресурсов при решении задачи технического нормирования. [Текст] / В.М. Самсонкін, В.С. Меркулов // Зб. наук. праць Київ. університету економіки і технологій трансп. - 2011. - Т. 19. - С. 153-164.

5. Меркулов, В.С. Структура моделі автоматизованої системи оперативного планування вантажно-розвантажувальних робіт в регіоні дороги [Текст] / В.С. Меркулов, І.Г. Бізюк // Зб. наук. праць Укр. держ. акад. залізнич. трансп. - 2014. - Вип. 149. - С. 9-12.

Рецензент д-р техн. наук, професор I.Е. Мартинов

Меркулов Віктор Сергійович, кандидат технічних наук, доцент кафедри обчислювальної техніки та систем управління, Український державний університет залізничного транспорту. Тел.: (057) 730-10-40. E-mail: twins54@yandex.ru.

Бізюк Ірина Григорівна, старший викладач кафедри обчислювальної техніки та систем управління, Український державний університет залізничного транспорту. Тел.: (057) 730-10-40. E-mail: igbiz@yandex.ru.

Merkulov Viktor Sergeyevich, candidate of technical sciences, associate Professor at computer and control systems Department of Ukrainian State Academy of Railway Transport, Tel.: (057) 730-10-40. E-mail: twins54@yandex.ru. Biziuk Iryna Grygoriyevna, Senior Lecturer at computer and control systems department of Ukrainian State Academy of Railway Transport, Tel.: (057) 730-10-40. E-mail: igbiz@yandex.ru.

Стаття прийнята 20.10.2015 p. 